\title{
A Contribution to the Understanding of the Combined Effect of Nitrogen and Boron in Grey Cast Iron
}

Strande, Knud; Tiedje, Niels Skat; Chen, Ming

Published in:

International Journal of Metalcasting

Link to article, DOI:

$10.1007 / \mathrm{s} 40962-016-0079-6$

Publication date:

2017

Document Version

Peer reviewed version

Link back to DTU Orbit

Citation (APA):

Strande, K., Tiedje, N. S., \& Chen, M. (2017). A Contribution to the Understanding of the Combined Effect of Nitrogen and Boron in Grey Cast Iron. International Journal of Metalcasting, 11(1), 61-70.

https://doi.org/10.1007/s40962-016-0079-6

\section{General rights}

Copyright and moral rights for the publications made accessible in the public portal are retained by the authors and/or other copyright owners and it is a condition of accessing publications that users recognise and abide by the legal requirements associated with these rights.

- Users may download and print one copy of any publication from the public portal for the purpose of private study or research.

- You may not further distribute the material or use it for any profit-making activity or commercial gain

- You may freely distribute the URL identifying the publication in the public portal 


\title{
A Contribution to the Understanding of the Combined Effect of Nitrogen and Boron in Grey Cast Iron.
}

\author{
Knud Strande ${ }^{1}$, Niels Tiedje ${ }^{2}$, Ming Chen $^{3}$ \\ ${ }^{1}$ Dansk Udviklings Formidling ApS, Bygaden 60, DK 2630 Taastrup, Denmark. \\ ${ }^{2}$ Technical University of Denmark, DTU, Mechanical Engineering, DK 2800 Lyngby, Denmark. \\ ${ }^{3}$ Technical University of Denmark, DTU, Energy Conversion and Storage, DK 4000 Roskilde, \\ Denmark.
}

\begin{abstract}
Inoculation is an essential part of controlling material properties in grey cast iron. Inoculation practice has for decades been based on the addition to the melt of small amounts of elements with strong affinity to $\mathrm{O}$ (and $\mathrm{S}$ ) just before casting takes place. This method is proven - both in theory and in practice - to be effective in most cases.

But it has the disadvantage that the nucleation effect fades away over time. Especially in heavy castings (slow cooling) this effect may cause non uniform and unacceptable material properties in some parts of the casting.

Nitrogen is also known to influence grey iron microstructure. Both graphite flake formation and matrix formation are influenced. However, the obtained effects differ considerably between different reported investigations.

This investigation deals with the combined effect of nitrogen and boron and how it in a simple way is possible to utilize this effect to enhance material properties in heavy grey iron castings.

It is shown that controlled addition of nitrogen and boron in practice can be used to control microstructure of heavy grey iron castings.

A plausible theory for formation of boron nitride nuclei effective for graphite growth is presented.
\end{abstract}

\section{Introduction.}

For centuries grey cast iron has been an important construction material in all kinds of machine design. This also applies to the production of large 2-stroke diesel engines, which still consist of many grey cast iron components. Cylinder frames and cylinder liners are the two single heaviest cast components in such engines. Their weights will together typically account for more than $15 \%$ of the total engine weight. Casting wall thicknesses of more than $200 \mathrm{~mm}$ are often seen.

During all years designers have struggled to enhance engine performance. The engine power/weight ratio has been increased continuously. This means that requirements to material properties have been increased accordingly. Especially requirements to grey iron cylinder liner material have been "pushed" close to what is possible to produce using a commercially viable foundry process.

Until recently the generally accepted idea of the ideal microstructure for a large 2-stroke cylinder liner has been: 
- As much free graphite of type A (ISO 945-1; uniform distributed) as possible, ensuring high thermal conductivity and excellent tribological abilities. High oil retaining capacity, low friction losses.

- A pearlitic matrix without ferrite, ensuring minimum local friction disturbance due to random areas of soft ferrite.

- 2 to $5 \%$ of evenly distributed, small-sized hard phase particles (carbides and phosphides) ensuring high abrasive wear resistance and at the same time minimizing the risk of scuffing caused by broken large-sized hard particles torn out of the liner surface.

At the same time requirements to material properties have for some liners increased to $\min .270 \mathrm{MPa}$ in tensile strength, and $\min 0.3 \%$ elongation before fracture. The requirement to chemical composition is (weight \%):

\begin{tabular}{|l|c|c|c|c|c|c|c|c|}
\hline Limit & C & Si & Mn & P & S & Cu & V & B \\
\hline Min. & 3.0 & - & - & 0.2 & - & 1 & - & 0.02 \\
\hline Nom. & 3.2 & 1.1 & 0.8 & - & - & - & - & - \\
\hline Max. & - & - & - & 0.4 & 0.10 & 1.5 & 0.22 & 0.040 \\
\hline
\end{tabular}

Table 1. Chemical composition specified for Tarkaloy A, MAN Diesel \& Turbo.

This mix of requirements may seem difficult to combine successfully in heavy sectioned castings. And in fact it is.

Over the years it has been somewhat a mystery how some foundries - with the given data - are able to meet specifications and others are not.

The following work has been driven by the author's curiosity to find a meaningful answer to this question.

\section{Practical experience and literature survey.}

To obtain the required material properties the foundry has the following general tools to work with:

1. Metal composition

2. Cooling rate

3. State of inoculation

4. Heat treatment

All tools available are to some extent applied (in different ways) in foundries producing the high end liners. The following analyses try to combine theoretical knowledge found in literature with "real foundry life experiences"

\section{Metal composition.}

In this case metal composition seems more or less to be given in advance.

However the possibility of micro alloying with suitable elements is possible. Micro alloying with strong carbide formers play an essential role obtaining the desired micro structure and material strength. In the material specification for Tarkalloy $A$, elements $V$ and $B$ represent 
the officially accepted micro alloying elements. Others can be used.

Addition of strong carbide formers ( $\mathrm{Mn}, \mathrm{Cr}, \mathrm{Mo}, \mathrm{Ti}, \mathrm{V}$ ) will typically increase tensile strength by reducing amount of free graphite and increase carbide content in matrix. However this is a dangerous road to expand when very slow cooling rates are involved. Carbides tend to grow to "over critical" sizes increasing the risk of scuffing.

Reducing the amount of free graphite reduces the thermal conductivity of the material and its ability to cope with inappropriate lubrication conditions. Once such "too big" and thermal stable carbides have developed they cannot be reduced by post cast heat treatment. $\mathrm{Cu}$ is added in order to secure a fully pearlitic matrix. Additional alloying with small amounts of strong pearlite stabilizing elements $(\mathrm{Sn}, \mathrm{Sb})$ are used to increase pearlite hardness thus increasing material strength. However, also this road must be tread with care. The material will typical be more brittle and may therefore not be able to fulfil the ductility requirement.

Nitrogen alone and in combination with other elements (nitrides) is also known to influence grey iron microstructure. Both graphite flake formation and matrix formation are influenced. Already in 1966, Mountford [1] concluded the main effects of $\mathrm{N}$ in grey cast iron, which are much in accordance with the predominantly perception of today:

- Nitrogen increases the strength of grey cast iron, partly by suppressing ferrite formation and partly by modifying the graphite structure, the flakes becoming shorter and more compact (before compact graphite iron was invented). This effect is most clearly seen in heavy sectioned castings.

- The beneficial effect of nitrogen on material properties is offset by addition of Ti and Al, which will take out $\mathrm{N}$ of solution by forming solid (carbo)nitrides.

- Too much nitrogen in the melt causes porosity defects due to the very limited solubility ( $\sim 80 \mathrm{ppm})$ of $\mathrm{N}$ in solid cast iron.

Although this knowledge has been available for half a century the exploitation in practical foundry operation has been very limited. User friendly equipment able to analyse small contents of the involved elements has not been available.

As the analysing equipment has become better (and cheaper) the interest in utilizing the $\mathrm{N}$ effect in order to enhance grey iron properties has had a revival.

Richards et al [2] have in several investigations refined the conclusions above, and Stets, Lötschert, and Wolf [3], have shown that the beneficial effect of nitrogen also apply to the fatigue strength of the material. They also give some practical guidelines how to add controlled amounts of nitrogen to the melt.

Some producers of high end cylinder liners for large 2-stroke diesel engines are also concerned with controlling the beneficial effect of $\mathrm{N}$.

\section{Cooling rate.}

Cooling rate can to some extent be influenced by using chills, which will speed up solidification of the surface layers involved, making micro structure finer and material 
strength higher in the material close to the chills. When using chills it must be taking into account that too high cooling rate at the inside surface may cause formation of excessive amount of hard phase, which may be difficult or impossible to remove later on.

Cooling rate in the interior of heavy castings is hardly affected by the application of chills when the casting still is surrounded by an insulating sand mould.

Early shake out at temperatures around $800^{\circ} \mathrm{C}$ is able to speed up cooling rate 5 to 10 times depending on local production set up and the actual casting involved. Increasing cooling rate during eutectoid transformation increases pearlite hardness/matrix strength and enhances overall strength of the material.

\section{Inoculation.}

Inoculation is an essential part of controlling grey iron microstructure. Normally, when talking inoculation foundry men specifically think of small additions of alloys creating nuclei able to precipitate graphite of desired type, size, and distribution in the casting. A lot of scientific work on the nucleation of graphite has been conducted during the past 50 years. All kinds of minor elements/compounds found in cast iron have been suggested possible provider of nuclei for graphite growth. Wallace [4] suggested in 1975 several rather different elements as possible nucleation substrates: crystalline graphite, local areas supersaturated with $\mathrm{Si}, \mathrm{SiC}$, dissolved $\mathrm{H}$ and $\mathrm{N}, \mathrm{BN}$, oxides and sulphides of $\mathrm{Al}, \mathrm{Ca}, \mathrm{Ba}$, $\mathrm{Sr}$, and rare earth metals. Later on also MnS was included [5].

Lampic and Walz [6] have recently looked at the different theories using theoretical physics and experimental results as "evaluation" tools.

This work excludes the BN theory as practical not feasible. Although hexagonal boron nitride has a crystal structure similar to graphite and in theory would be the ideal substrate for graphite to grow from, the idea is rejected. Due to high affinity of boron to oxygen they judge the BN-theory not being able to work in practice.

This statement is to some extent contradicted by [7], which demonstrates that hexagonal boron nitride precipitations exists in graphite particles in B-doped graphitized steel sheet. Until now the existence of $\mathrm{BN}$-particles as nuclei for graphite precipitation in grey cast iron has not been physical verified, but in [8], a US patent from 2006 it is claimed that "the addition of boron in amounts between $10 \mathrm{ppm}$ and $150 \mathrm{ppm}$ by weight effectively combines with nitrogen dissolved in the molten iron and thus serves to minimize the influence of nitrogen on the stability of carbides and pearlite and also forms BN particles, which can serve as nuclei for the precipitation of graphite".

The many contradicting results [9] obtained when investigating the influence of boron in cast iron may be explained by the lack of control of other "important" minor elements $(\mathrm{N}$, $\mathrm{Ti}, \mathrm{Al})$ strongly influencing the overall effect.

The nucleation theory, commonly accepted and beautiful documented [10], are the heterogeneous nucleation theory, which today is the basis for inoculation procedures applied in foundries all over the world. Small amounts of elements with strong affinity to $O$ (and S) are added to the melt just before casting takes place. Under the right conditions small particles of oxides will precipitate in the melt serving as effective nuclei for graphite 
growth. Such inoculants are commercially available products, typically based on a FeSi alloy also containing one or more of the elements $\mathrm{Al}, \mathrm{Ca}, \mathrm{Zr}, \mathrm{Sr}, \mathrm{Ba} \ldots .$.

This method is proven to be effective in most cases.

But it has the disadvantage that the nucleation effect fades away over time due to coalesce of the precipitated oxides transforming the effective nuclei into ineffective slag particles. Especially in heavy castings (slow cooling) this effect may cause unacceptable material properties in some part of the casting.

Nucleation of primary austenite in cast iron is a subject that has drawn much less attention in the foundry community than graphite nucleation. But over time it is possible to find scientific work claiming that the solidification mode of primary austenite dendrites also influences graphite nucleation and overall material properties. Kamaya and Murai [11] have long ago shown that the austenite/graphite eutectic has optimum (many eutectic cells, uniform distributed, random orientated A-graphite) growth conditions in a melt containing fine developed primary austenite dendrites with many junctions. The reason for this may be an accumulation in the adjacent melt of elements that cannot be dissolved in the austenite. Some of those elements are potential nuclei for graphite precipitation. To the authors this model intuitively makes good sense.

Ruff and Wallace [12] have shown $\mathrm{Al}, \mathrm{Ti}$, and $\mathrm{V}$ to increase the number of dendrites and their lengths.

Also $\mathrm{Nb}$ has been shown [13] to refine both dendrite and eutectic cell structure in grey cast iron.

Recently Muhmond and Frederiksson [14,15] have contributed to a better understanding of the MnS formation mechanism in cast iron and its role in the nucleation of austenite as well as of graphite. In order for MnS to nucleate homogenously in the melt $\mathrm{C}_{\mathrm{Mn}} \mathrm{C}_{\mathrm{S}}$ must be $>0.0126$. Inoculation significantly increases the number of MnS particles by creating solid oxides/sulphides in the melt serving as nucleation sites for MnS.

This investigation gives a theoretical explanation to the generally accepted experience that most inoculants show lower performance when S-content of the melt is below $\sim 0.04 \%$.

\section{Heat treatment.}

If the cylinder liner casting has been removed from the mould at (liner) temperatures above $300^{\circ} \mathrm{C}$ a stress relieving heat treatment after rough machining is specified.

Sometimes this heat treatment - besides reducing residual stresses - also causes slightly increased material strength giving the impression that some sort of precipitation hardening has happened.

Among others Anish, Lekakh, and Richards [2] has shown that nitrogen under certain conditions will precipitate from supersaturation in ferrite to a more stable phase $\mathrm{Fe}_{4} \mathrm{~N}\left(\gamma^{\prime}\right)$ causing a hardening effect. This reaction will run slowly at room temperature (days) and quick at $250^{\circ} \mathrm{C}$. If the material is further heated up to $560^{\circ} \mathrm{C}$ a ternary eutectic reaction will take place also involving the cementite part of the matrix: $\mathrm{y}^{\prime}+\alpha-\mathrm{Fe}+\mathrm{Fe}_{3} \mathrm{C} \rightarrow \mathrm{\gamma}+\mathrm{C}$. According to [2] both reactions result in hardening effects. 
Elements with strong affinity to nitrogen - like $\mathrm{Ti}$ - will reduce or eliminate this age hardening effect by tying up nitrogen to "inactive" $\mathrm{Ti}_{3} \mathrm{~N}$.

This theory seems to be in agreement with practical life experience. Common for the producers able to make top end liners meeting actual requirements without problems are:

1. Nitrogen content of the iron between 70 and $100 \mathrm{ppm}$.

2. Content of $\mathrm{Ti}$ and $\mathrm{Al}$ is low $(\mathrm{Ti}<0.015 \%$ and $\mathrm{Al}<0.010 \%)$.

3. Stress relieving heat treatment at temperatures close to $600^{\circ} \mathrm{C}$.

The other available tools (micro alloying, cooling rate, inoculation) are used more individually by the single foundry depending on local experience and actual production equipment.

Based on the above analysis the following statements regarding the combined effect of $\mathrm{B}$ and $\mathrm{N}$ in grey cast iron are made.

Under the right conditions, which is rather simple to establish with today's foundry equipment, several beneficial effects can be utilized in practical foundry operation by a controlled addition of nitrogen and boron:

1. In slow cooling castings hexagonal boron nitride, BN, precipitate from the melt at temperatures close to eutectic temperature and serve as nucleation sites for graphite growth resulting in a uniform distribution of graphite flakes.

2. Graphite growth conditions are - for some reason - running in "nitrogen" mode creating shorter and more compact flakes than seen in cast iron without nitrogen.

3. Excess boron - surplus from hexagonal boron nitride formation - forms boron carbides stabilizing a pearlitic phase making matrix harder and stronger.

4. Excess nitrogen - not tied up by hexagonal boron nitride (and TiN, AIN) formation dissolved in austenite and supersaturated dissolved in ferrite gives rise to age hardening of the pearlite when heating to $>560^{\circ} \mathrm{C}$ due to precipitation of $\mathrm{Fe}_{4} \mathrm{~N}\left(\gamma^{\prime}\right)$. Some sort of "over aging" may be a consequence when time at elevated temperature is extended. Carbon will be pulled out of the cementite phase and placed on the graphite increasing the amount of free graphite thus reducing the overall hardness (and strength) of the material.

In an attempt to quantify the above statements an experiment was set up.

\section{Experimental}

\section{Metal composition.}

\begin{tabular}{|c|c|c|c|c|c|c|c|c|c|c|}
\hline $\mathrm{C}$ & $\mathrm{Si}$ & $\mathrm{Mn}$ & $\mathrm{P}$ & $\mathrm{S}$ & $\mathrm{Cu}$ & $\mathrm{B}$ & $\mathrm{N}$ & $\mathrm{V}$ & $\mathrm{Ti}$ & $\mathrm{Al}$ \\
\hline 3.25 & 1.0 & 0.5 & 0.25 & 0.07 & 0.5 & 0.025 & 0.01 & $<0.01$ & $<0.01$ & $<0.01$ \\
\hline
\end{tabular}

Table 2. Target metal composition, weight \%.

All other trace elements were intended to be kept low. 
The low content of $\mathrm{V}, \mathrm{Ti}$, and $\mathrm{Al}$ was chosen in order to minimize their "disturbing" influence on the formation of hexagonal BN.

The nitrogen content of $100 \mathrm{ppm}$ was chosen in order to provide sufficient $\mathrm{N}$ for both BN formation and solid solution strengthening - and to minimize the risk of porosity defects caused by too high $\mathrm{N}$ content.

The $\mathrm{Mn}$ and $\mathrm{S}$ content was chosen in order to provide optimum conditions for an early formation of MnS in the melt thus providing nuclei for austenite and graphite formation. The $\mathrm{P}$ content was chosen in order to create the desired fine network of wear resistant iron phosphide $\left(\mathrm{Fe}_{3} \mathrm{P}\right)$. Addition of $\mathrm{P}$ also has the effect of expanding the eutectic solidification range facilitating the growth of graphite nucleated on $\mathrm{BN}$, which according to phase equilibrium calculations starts formation at almost same temperature as graphite, see figure 1.

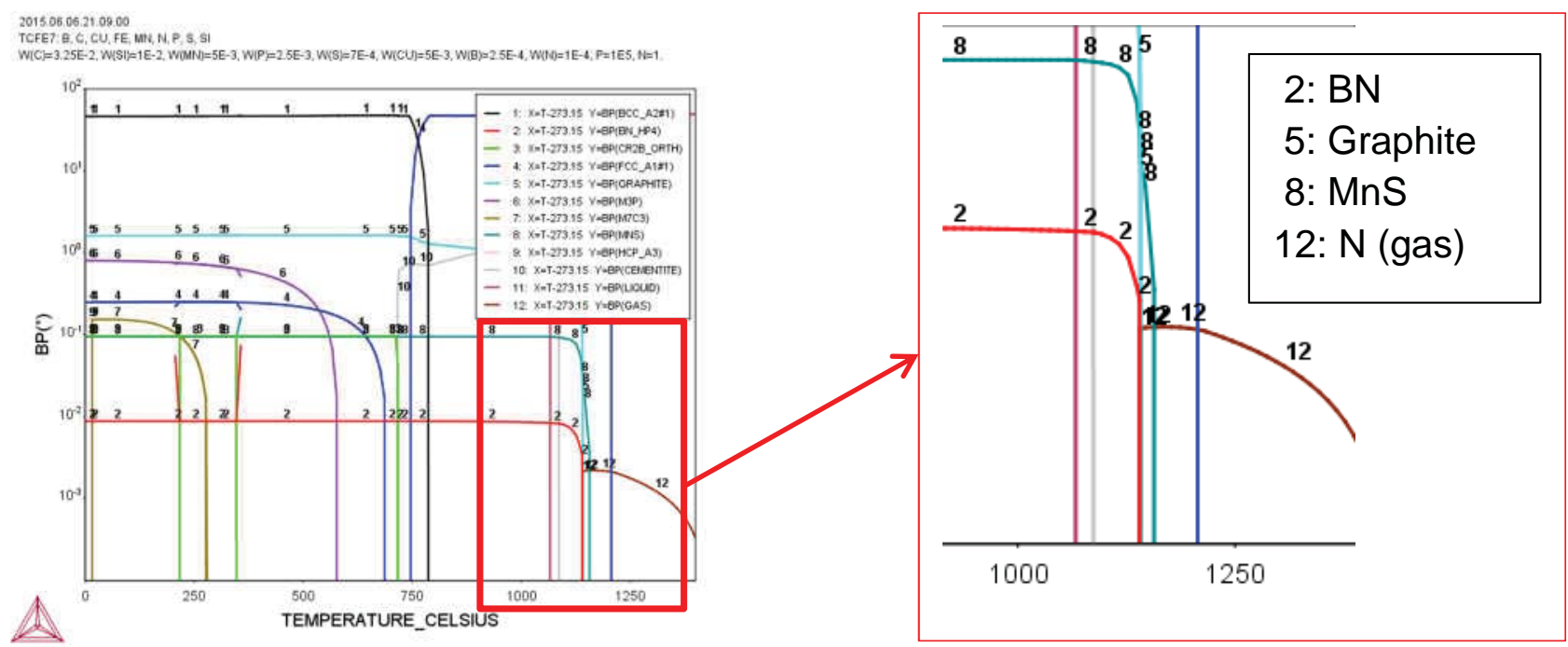

Figure 1. The solidification range is according to thermocalc calculations expanded downwards from $\mathrm{Ts} \sim 1130^{\circ} \mathrm{C}$ to approximately $1090^{\circ} \mathrm{C}$ by adding $0.25 \% \mathrm{P}$.

$\mathrm{BN}$ and graphite starts precipitation at $\sim 1145^{\circ} \mathrm{C}$. MnS starts precipitation at $\sim 1160^{\circ} \mathrm{C}$.

Addition of $\mathrm{P}$ means that the time for $\mathrm{B}$ and $\mathrm{N}$ to "mate" and for optimal graphite growth conditions to exist will increase considerably. Of course this effect also depends on casting size (cooling rate).

As an anecdote; in 2006 Pokrovsky [16] presented some data that supported a "phosphorous nucleation theory" stating that addition of $\mathrm{P}$ improved the state of nucleation in grey cast iron.

\section{Test casting.}

The test casting is a vertically cast solid rod $\varnothing 180 / 200 \mathrm{~mm} \times 460 \mathrm{~mm}$ poured in a sodium silicate bonded sand mould with an $\varnothing 200 \times 200 \mathrm{~mm}$ insulating feeder on top. Total weight $\sim 130 \mathrm{~kg}$.

Two thermocouples were placed at height $\sim 300 \mathrm{~mm}$ from the bottom of the casting for cooling curve recording. One positioned at the mould/metal interface, the other positioned 
$5 \mathrm{~mm}$ from the mould wall inside the casting.

The casting was cooled to $\mathrm{T}<300^{\circ} \mathrm{C}$ before shake out took place.

Geometry of the test casting is illustrated in figure 2 .

Slices approximately $35 \mathrm{~mm}$ thick were cut and used for different heat treatments and determination of material properties and microstructure.
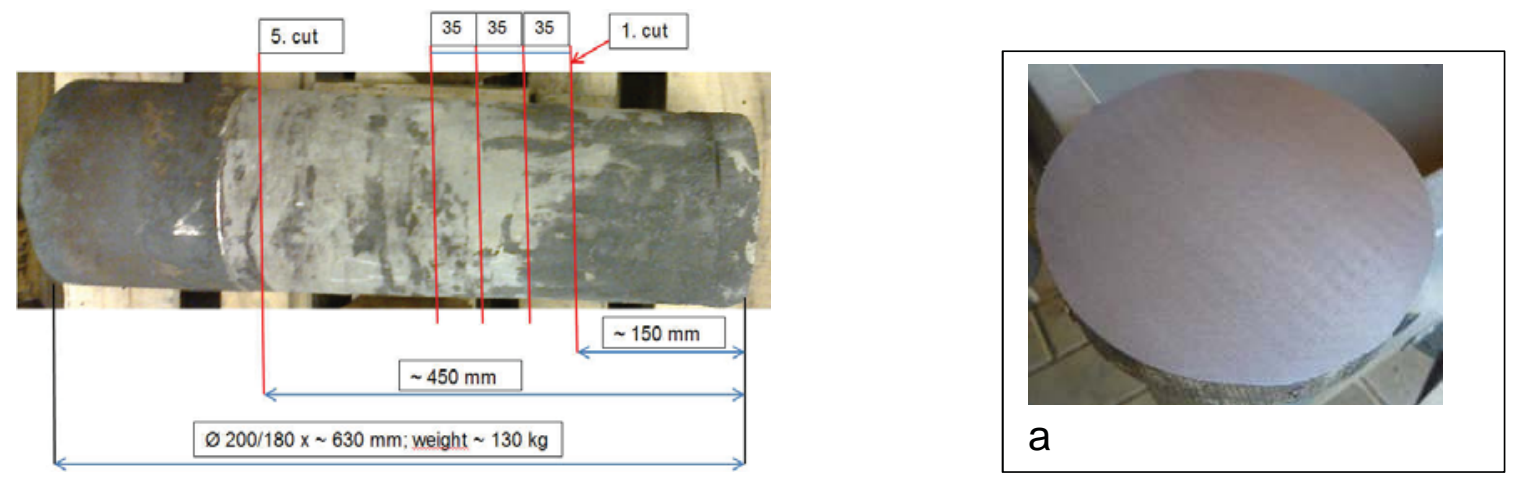

Figure 2.

The test casting is a vertically cast solid rod $\varnothing 180 / 200 \mathrm{~mm} \times 460 \mathrm{~mm}$ with an $\varnothing 200 \times 200$ $\mathrm{mm}$ insulating feeder on top. Total weight $\sim 130 \mathrm{~kg}$.

Fig. 2 a shows a machined slice cut from the test casting. From each slice it is possible to machine 3 tensile test pieces - ISO 185 type B with test diameter $\varnothing 16 \mathrm{~mm}$. Those test pieces are also used for determination of material structure and hardness.

Besides the test casting itself the following test items were made from the melt for control purposes:

- Two white solidified coupons for chemical analysis.

- 2 ps. separately cast Ø30 $\mathrm{mm}$ tensile test pieces (ISO 185).

- One thermal analysis.

\section{Melt treatment.}

The charge was melted in an acid lined $150 \mathrm{~kg}$ medium frequency induction furnace. The charge material was made up of (in the following order): pig iron, foundry return, steel plate, and carburizer. When all melted, T was raised to $\sim 1500^{\circ} \mathrm{C}$ and kept constant for about a 20 min. carbon boil. Thus the melt could be considered as clean and relatively poor of nuclei. The chemical composition (except $\mathrm{N}$ ) was adjusted by adding the necessary amount of different ferroalloys. The target $\mathrm{N}$ content of $100 \mathrm{ppm}$ was intended achieved by adding calcium cyan amide $\left(\mathrm{CaCN}_{2}\right)$ in bottom of the pouring ladle during metal transfer.

No conventional inoculation was performed.

The test casting was poured at $1300^{\circ} \mathrm{C}$.

\section{Material investigations.}

Determination of material properties and microstructural analysis were performed on one 
as cast slice (designated A2) and on one stress relieved slice (designated A3).

For reference the two separately cast $\varnothing 30 \mathrm{~mm}$ test pieces were treated likewise.

Stress relieving cycle: Heating to $600^{\circ} \mathrm{C}, 6 \mathrm{~h}$; holding at $600^{\circ} \mathrm{C}$ for $10 \mathrm{~h}$; cooling in furnace until $\mathrm{T}<300^{\circ} \mathrm{C}$.

\section{Results and discussion}

\section{Chemical composition}

\begin{tabular}{|c|c|c|c|c|c|c|c|c|c|c|c|}
\hline $\mathrm{C}$ & $\mathrm{Si}$ & $\mathrm{Mn}$ & $\mathrm{P}$ & $\mathrm{S}$ & $\mathrm{Cu}$ & $\mathrm{B}$ & $\mathrm{N}$ & $\mathrm{Cr}$ & $\mathrm{V}$ & $\mathrm{Ti}$ & $\mathrm{Al}$ \\
\hline 3.25 & 1.0 & 0.44 & 0.25 & 0.08 & 0.44 & 0.026 & 0.013 & 0.06 & 0.017 & 0.007 & 0.005 \\
\hline
\end{tabular}

Table 3. Achieved metal composition

Except nitrogen content the actual metal composition is rather close to target composition. The N "overflow" is due to the applied "non commissioned" addition procedure.

The high nitrogen content caused some gas porosities in top of the casting below the feeder. However, sound slices could be cut from the lower part of the casting.

For practical foundry operation it is of course essential to be more precise with the $\mathrm{N}$ content and identify a "fail safe" melting procedure able to control nitrogen content within desired limits.

In an electric melting shop the better way to do so seems to be a control of nitrogen content of the base melt in the furnace just before metal is transferred to the pouring ladle - like it is done for all other important alloying elements. This means that the single foundry must know the $\mathrm{N}(\mathrm{Al}, \mathrm{Ti} \ldots)$ content of their charge materials and how the applied melting procedure influences final $\mathrm{N}$ content.

Some commercial recarburizing materials also contain nitrogen. This may be - depending on charge make up - a viable nitrogen source. Other applicable nitrogen sources are nitrogen containing FeMn and $\mathrm{FeCr}$, or as applied in this study, $\mathrm{CaCN}_{2}$.

In cupola melting shops the iron normally is "born" with relatively high nitrogen content, $100 \mathrm{ppm}$. Here is the task to control the level of nitrogen "getters" (Ti, Al...) in order to utilize the beneficial effect of nitrogen in a controlled manner. 
Mechanical properties

\begin{tabular}{|c|c|c|c|c|c|}
\hline Specimen & $\begin{array}{c}\mathrm{Rm} \\
{[\mathrm{MPa}]}\end{array}$ & $\begin{array}{l}\text { Atot } \\
{[\%]}\end{array}$ & $\begin{array}{c}\text { E-modulus } \\
\text { [GPa] }\end{array}$ & $\begin{array}{c}\text { Hardness } \\
\text { HBW 10/3000 }\end{array}$ & \multirow{4}{*}{$\begin{array}{l}\text { Hardness, HV25 g } \\
\text { Average of } 5 \\
\text { impressions in } \\
\text { pearlite structures } \\
\text { of A2-2. }\end{array}$} \\
\hline A2-1 & 203 & 0.73 & 122 & 170 & \\
\hline A2-2 & 200 & 0.62 & 146 & 165 & \\
\hline A2-3 & 200 & 0.71 & 161 & NA & \\
\hline $\mathrm{A} 2$ & 201 & 0.69 & 143 & 168 & 272 \\
\hline A3-1 & 214 & 0.65 & 161 & 164 & \multirow{3}{*}{ A3-2 } \\
\hline A3-2 & 204 & 0.61 & 153 & 165 & \\
\hline A3-3 & 215 & 0.74 & 140 & NA & \\
\hline A3 & 211 & 0.67 & 151 & 165 & 303 \\
\hline
\end{tabular}

Table 4. Mechanical properties of test casting. A2 represents values obtained on an as cast test slice; A3 represents values obtained on a stress relieved test slice.

Test results tell an overall story of a material showing:

1. Rather good and uniform material properties approximately meeting expectations to material strength of alloy ISO 185/JL/300 cast in a similar wall thickness. Emodulus and elongation are at the high end; material hardness at the low end of the expected interval.

2. The applied stress relieving heat treatment causes an increase in tensile strength of $10 \mathrm{MPa}$, in E-modulus an increase of $8 \mathrm{GPa}$, and an increase in micro hardness of the pearlite of $31 \mathrm{HV}$. The macro hardness and elongation have decreased marginally.

3. The relative hardness, $\mathrm{RH}$, - the relation between HBW and $\mathrm{Rm}$ as defined in ISO 185 - of the material is low; 0.89 for the as cast sample and 0.86 for the SRsample. Low RH values indicate the presence of a Low amount of hard phase/high amount of eutectic graphite in the casting.

So far, the initial statements of section 3 have not been contradicted.

Mechanical properties of the separately cast $\varnothing 30 \mathrm{~mm}$ test pieces are shown in table 5 .

\begin{tabular}{|c|c|c|c|}
\hline Specimen & $\begin{array}{c}\text { Rm } \\
{[\mathrm{MPa}]}\end{array}$ & $\begin{array}{c}\text { Hardness } \\
\text { HB30 }\end{array}$ & $\begin{array}{c}\text { Relative hardness } \\
\mathrm{RH}\end{array}$ \\
\hline$\varnothing 30$ as cast & 230 & 230 & 1.14 \\
\hline$\varnothing 30$ stress relieved & 230 & 180 & 0.89 \\
\hline
\end{tabular}

Table 5. Mechanical properties of the separately cast $\varnothing 30 \mathrm{~mm}$ test pieces.

The obtained tensile strength values do not correspond to the minimum requirement, 300 $\mathrm{MPa}$, of alloy ISO 185/JL/300. The high hardness indicates that massive carbides and a low amount of eutectic graphite are present in the as cast sample. It seems - in other words - that the state of inoculation has been inadequate for the actual combination of metal composition and cooling rate. 
Stress relieving reduces hardness dramatically. As shown in next section this is caused by a significant reduction of hard phase present in the stress relieved sample.

\section{Micro structure}

The micro structure has been examined in different ways:

1. A standardized MAN B\&W procedure based on an automated computerized Image Analysing System. Graphical outcome of the A2-2 analysis is shown in figures 5 and 6.

2. A more individual look at specific "interesting" findings. Examples of this are shown in figures 3 and 4.

3. Electron scanning microscope (SEM with EDS and WDS for elementary analysis) in a pious hope to find physical evidence of hexagonal boron nitride together with graphite flakes.

Microstructure of the two $\varnothing 30 \mathrm{~mm}$ test pieces has been manually evaluated with the following results:

\begin{tabular}{|c|l|}
\hline Specimen & \multicolumn{1}{c|}{ Microstructure } \\
\hline$\varnothing 30$ as cast & $\begin{array}{l}\text { Fine lamellar graphite in a matrix of pealite (dark) surrounded } \\
\text { by hard phase steadite (gey). See figure 3. } \\
\text { Hard phase share } ~ 15 \% .\end{array}$ \\
\hline$\varnothing 30$ stress relieved & $\begin{array}{l}\text { Fine lamelar graphite in a matrix of pealite (dark). } \\
\text { Light areas are hard phase mainly consisting of iron phosphide. } \\
\text { Hard phase share is now reduced to 3- 4\%. } \\
\text { The cementite part of the steadite has been broken down to } \\
\text { graphite and perlite during the heat treatment. See figure 4. }\end{array}$ \\
\hline
\end{tabular}

Table 6. Characterisation of microstructure - $\varnothing 30 \mathrm{~mm}$ test pieces.

As cast structure consists of fine lamelar graphite in a matrix of pealite (dark) surrounded by hard phase steadite (gey). Hard phase share $~ 15 \%$.

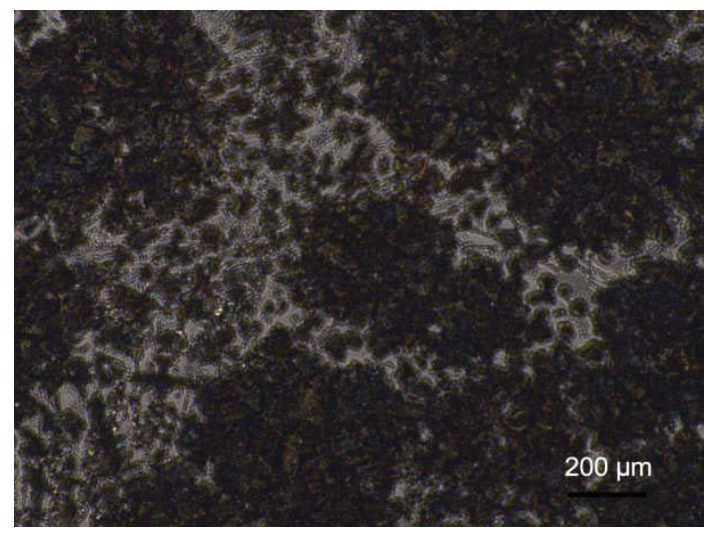

Figure 3. $\varnothing 30 \mathrm{~mm}$ as cast etched structure. Hard phase share $\sim 15 \%$. Eutectic cell size $0.5 \mathrm{~mm}$. 
Stress relieved micro structure, figure 4, consists of fine lamelar graphite in a matrix of pearlite (dark). Light areas are hard phase mainly consisting of iron phosphide.

Hard phase share is now reduced to 3- $4 \%$.

The cementite part of the steadite has been broken down to graphite and perlite during the heat treatment. A "close up" of the resulting hard phase is shown in figure 4a.

Small (dark) islands of pearlite inside the iron phosphide phase (light) are seen. This structure is a dissolved steadite probably possible to obtain by the low temperature heat treatment because of the low content of strong carbide forming elements.

This means that the hard phase here is constituted mainly by iron phosphide and that the amount can be controlled by the amount of phosphorous present in the alloy in combination with a simple low temperature heat treatment.

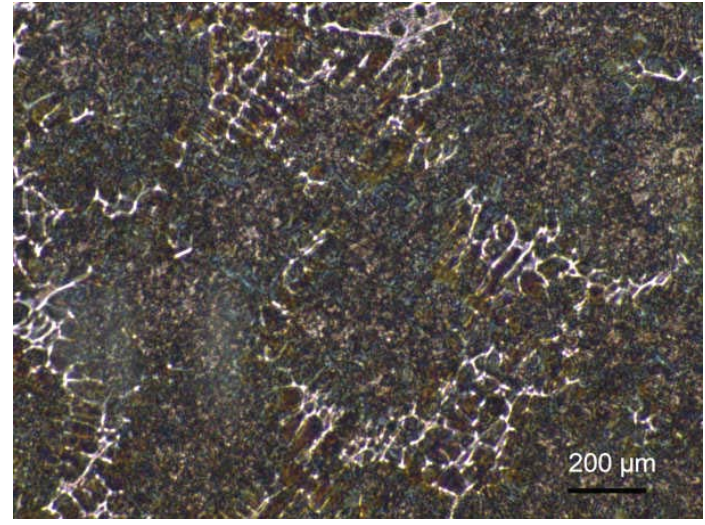

Figure 4. $\varnothing 30 \mathrm{~mm}$ stress relieved structure. Figure $4 \mathrm{a}$ is a "close up" of the hard phase structure showing small (dark) islands of pearlite inside hard phase iron phosphide (light).

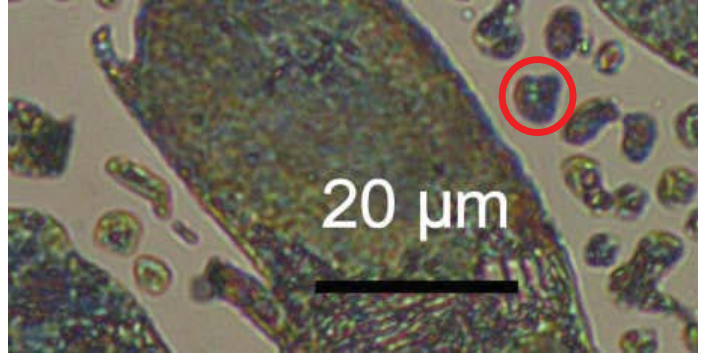

$4 a$. 
Microstructure of the test casting has been evaluated using a MAN B\&W standardized IAS procedure.
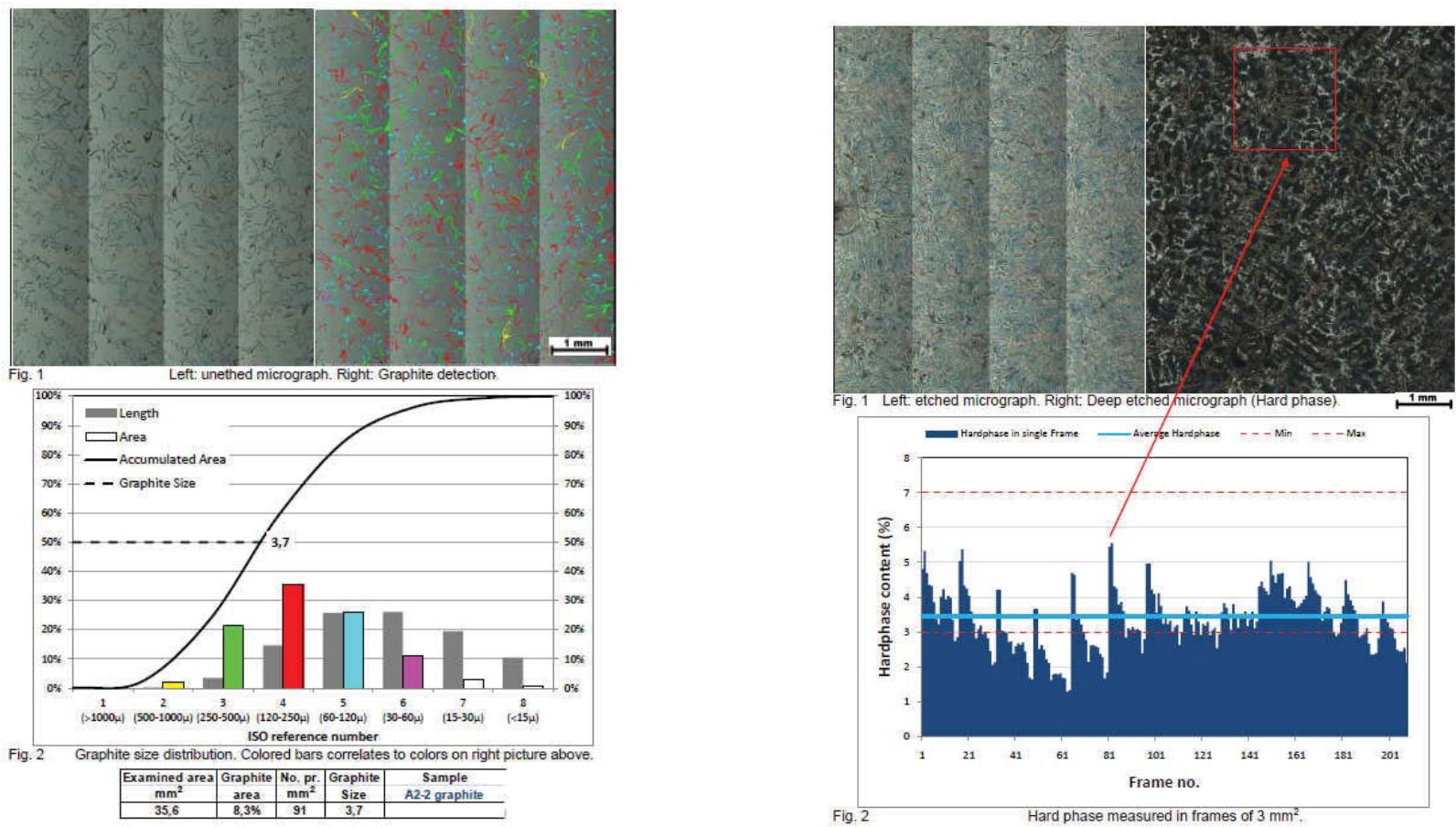

Figure 5 and 6 show the outcome of the computerized image analyses of sample A2-2.

The hard phase distribution in figure 6 is nicely uniform. Eutectic cell size is in the order of $1 \mathrm{~mm}$.

Similar uniform distribution of hard phase is found in all test pieces from the test casting indicating that the "state of inoculation" has been good, supporting the boron nitride nucleation theory.

However, it has not been possible to demonstrate the physical evidence of hexagonal BN in the test casting using the electron microscopes available for this project. That leaves the BN nucleation statement somewhat weakened as the found "good state" of inoculation might have been caused by the precipitated MnS particles, which are easily seen all over the structure.

In table 7 translations of figures 5 and 6 to readable numbers (ISO 945 reference numbers) are shown together with the results for sample A3-2.

\begin{tabular}{|c|c|c|c|c|c|c|c|}
\hline Specimen & \multicolumn{2}{|c|}{$\begin{array}{c}\text { Graphite type and } \\
\text { size }\end{array}$} & Graphite & $\begin{array}{c}\text { Graphite } \\
\text { Area }\end{array}$ & \multicolumn{2}{c|}{ \% hard phase } & \% Ferrite \\
\cline { 2 - 8 } & Type & Size & No. $\mathrm{mm}^{2}$ & $\%$ & Average & Max. & Average \\
\hline A2-2 & I A 3/4/5 & 3.7 & 91 & 8.3 & 3.4 & 5.5 & $<1$ \\
\hline A3-2 & I A 3/4/5 & 3.7 & 85 & 8.8 & 3.3 & 5.3 & $<1$ \\
\hline
\end{tabular}

Table 7. Characterisation of microstructure - test casting. 
Figures of table 7 look more or less the same for the two test items. Only a slight increase in free graphite and a minor decrease in hard phase content are noticed for the stress relieved sample.

A closer look at a less intensive etched microstructure reveals that graphite shape appears in a "compact" form typical for nitrogen alloyed grey iron.

A colour graduation - not seen in the deep etched structure used for hard phase determination - of the matrix from dark to light towards some of the graphite lamella can be seen.

Ferrite islands can be found adjacent to some graphite lamella. An illustration thereof is shown in the stress relieved structure of figure $7 a$.
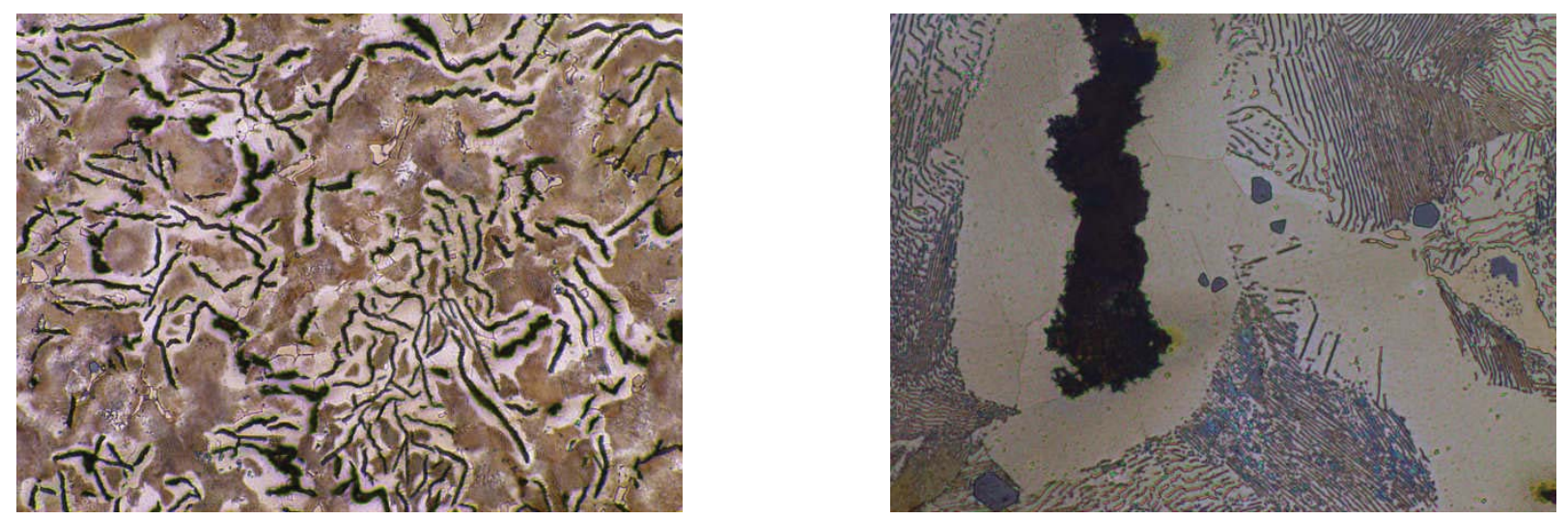

Figure 7. Moderately etched microstructure of A3-2 showing colour graduation indicating carbon depletion close to the graphite lamella.

Figure 7a. Graphite flake surrounded by ferrite. Figure also illustrates the typical compacted graphite form seen in nitrogen alloyed grey cast iron.

The carbon depletion seen in the stress relieved sample is in line with the extra free graphite determined in A3-2. Carbon has been pulled out of some of the existing cementite and transferred to the graphite flakes during low temperature heat treatment. This also explains the experienced slight decrease in macro hardness despite the measured increase in micro hardness of the pearlite in the stress relieved material.

The more or less constant amount of hard phase found in both test pieces indicate that the hard phase measured in both cases mainly consist of iron phosphide. Primary steadite - if any formed - has due to the slow in mould cooling rate - already in the as cast state been changed to $\mathrm{Fe}_{3} \mathrm{P}+\mathrm{C}+$ pearlite.

Thus the stress relieving heat treatment has a dual effect:

1. Precipitation hardening causing a harder and stronger matrix.

2. Moving carbon from the matrix material to the graphite flakes causing a softer and weaker matrix. The amount of free graphite increases.

In order to optimize the age hardening effect of nitrogen an additional condition must be fulfilled. The applied heat treatment cycle must be optimized depending on casting section thickness and alloy composition. 


\section{Conclusions}

1. Although the physical existence of hexagonal BN has not been demonstrated strong evidence of its existence as graphite nucleating sites in slow cooling grey cast iron has been demonstrated.

Provided controlled content of vital trace elements is enforced small amounts of boron and nitrogen causes uniform microstructure as well as good material properties all over the cross section of heavy castings.

2. Graphite growth conditions are running in "nitrogen" mode creating short and compact flakes.

3. Dissolved nitrogen - not tied up by hexagonal boron nitride (and TiN, AIN) formation - gives rise to age hardening of the pearlite when heating to $>560^{\circ} \mathrm{C}$.

4. Some sort of "over aging" may be a consequence when time at elevated temperature is extended.

5. In phosphorous alloyed wear resisting materials (cylinder liners) it is possible to achieve a specific, constant amount of hard phase evenly distributed in all part of the casting.

It is possible to implement those findings in practical foundry operation without big fuss. The first step will be a routine control of trace elements in the melt. Today's analysing equipment can do the job together with motivated melting shop operators.

\section{Acknowledgement}

This work has been made possible by the support from:

1. MAN Diesel \& Turbo, Copenhagen, Denmark.

2. Vald. Birn A/S, Holstebro, Denmark.

3. Brdr. Christensen ApS, Denmark.

\section{References}

[1] F. A. Mountford; The British Foundryman (April 1966), p 141-151.

[2] T. Anish, S. N. Lekakh, and V. L. Richards; AFS Transactions 96 (2008), p 653-663.

[3] W. Stets, A. Lötschert, and G. Wolf; Giesserei 95 (2008) no. 11, p 42-57.

[4] J. F. Wallace; AFS Transactions 83 (1975) 363-378.

[5] A. Sommerfeld and B. Tonn; Giesserei 95 (2008) no. 8, p 72-74.

[6] M. Lampic and M. Walz; Giesserei 100 (2013) no. 3, p 54-64.

[7] T. Mega, R. Morimoto, M. Morita, and J. Shimomura; Surface and Interface Analyses 24 (1996), p 375-379.

[8] Patent WO 2006133355 A2; Cast iron alloy containing boron.

[9] P. Fosland and A. Engebretsen; SINTEF-report no. STF 51 A 73003; NTH 1973. 
[10] K. Orths and W. Weis; Giessereiforschung 25 (1973) no. 1, p 9-19.

[11] N. Kamaya and K. Murai; Report of the Casting Research Laboratory, Waseda University, Japan no. 29 (1978), p 1-6.

[12] G. F. Ruff and C. F. Wallace; AFS Transactions 84 (1976), p 705-729.

[13] H. Mohrbacher; Gjuteriet 6 (2005), p 24-25.

[14] H. M. Muhmond and H. Frederiksson; Metallurgical and Material Transactions B (44B) (April 2013), p 283-298.

[15] H. M. Muhmond and H. Frederiksson; Trans Indian Inst Met 66 (April 2013), p 185-192.

[16] Y. K. Pokrovsky; Bryansk Engineering Works (2006); personal communication. 